\title{
Evidence of integumentary scale diversity in the late Jurassic Sauropod Diplodocus sp. from the Mother's Day Quarry, Montana
}

\author{
Tess Gallagher ${ }^{\text {Corresp., } 1}$, Jason Poole ${ }^{2}$, Jason P Schein ${ }^{2}$ \\ 1 Biology Department, Union College, Schenectady, New York, United States \\ 2 Bighorn Basin Paleontological Institute, Philadelphia, Pennsylvania, United States \\ Corresponding Author: Tess Gallagher \\ Email address: gallaght@union.edu
}

The life appearance of dinosaurs is a hotly debated topic in the world of paleontology, especially when it comes to dinosaur integument. In the case of sauropods, however, the topic is harder to properly discuss due to the limited amount of fossilized skin impressions that have been discovered. Thus far, the fossil record of sauropod integument fossils include titanosaur embryos from Patagonia, possible keratinous diplodocid dorsal spines, track ways with foot impressions, and other isolated skin impressions found in association with sauropod body fossils. Several prominent skin impressions have been found at the Mother's Day Quarry, located in the Bighorn Basin, Montana. These discoveries may bring new important information about diplodocids, specifically Diplodocus sp. Here we describe newly uncovered fossilized skin that gives evidence of scale diversity in the Diplodocid genus Diplodocus. The scales themselves represent tubercles, and exhibit various shapes including rectangular, ovoid, polygonal, and globular scales. The tubercles are small in size, the biggest of which only reach about $10 \mathrm{~mm}$ in length. Considering how diverse the scale orientation is in such a small area of skin, it is possible that these distinct scale shapes may represent a transition on the body from one region to another: perhaps from the abdomen to dorsal side, or abdomen to shoulder. Based on analysis of extant integument and scale orientation of crocodilians and other reptiles, it is possible to hypothesize on the location of the integument relative to the body as well as the size and relative maturational status of the individual. 
1 Evidence of Integumentary Scale Diversity in the Late Jurassic

2 Sauropod Diplodocus sp. from the Mother's Day Quarry,

3 Montana

4 Tess Gallagher1, Jason C. Poole2 and Jason P. Schein2

5 1Union College, Schenectady, NY 2 Bighorn Basin Paleontological Institute, Philadelphia, PA

6 Abstract

7 The life appearance of dinosaurs is a hotly debated topic in the world of paleontology, especially

8 when it comes to dinosaur integument. In the case of sauropods, however, the topic is harder to

9 properly discuss due to the limited amount of fossilized skin impressions that have been from Patagonia, possible keratinous diplodocid dorsal spines, track ways with foot impressions, and other isolated skin impressions found in association with sauropod body fossils. Several prominent skin impressions have been found at the Mother's Day Quarry, located in the Bighorn Basin, Montana. These discoveries may bring new important information about diplodocids, specifically Diplodocus sp. Here we describe newly uncovered fossilized skin that gives evidence of scale diversity in the Diplodocid genus Diplodocus. The scales themselves represent tubercles, and exhibit various shapes including rectangular, ovoid, polygonal, and globular scales. The tubercles are small in size, the biggest of which only reach about $10 \mathrm{~mm}$ in length. Considering how diverse the scale orientation is in such a small area of skin, it is possible that these distinct scale shapes may represent a transition on the body from one region to another: perhaps from the abdomen to dorsal side, or abdomen to shoulder. Based on analysis of extant integument and scale orientation of crocodilians and other reptiles, it is possible to hypothesize on the location of the integument relative to the body as well as the size and relative maturational status of the individual.

\section{Introduction}

Life depictions of dinosaurs have changed considerably over time as a result of new discoveries and a better understanding of functional morphology. The most prominent example being the presence of feathers in several dinosaur clades (e.g., Xu et al., 2012), which has generated great interest in the evolution of birds and feathers, and ultimately changed how we view dinosaurs. However, our understanding of scaley dinosaur integument has also changed. Over the past century, the number of studies published on dinosaur scales has dramatically increased (e.g., Brown et al., 2017, Bell, 2014, Bell and Hendrickx, 2020). Despite this, research into sauropod integument remains rather limited compared to research on other dinosaur integument. Some of the best-preserved sauropod skin comes from titanosaur embryos in Patagonia (Coria and Chiappe, 2007), which show that these animals would have had diverse scale shapes and sizes as well as diverse patterns in terms of how the scales are oriented. Other information on sauropod skin is limited to footprints and skin impressions that show mosaic or pebble like patterning (Platt and Hasiotis, 2006, Gimenez, 2007, Kim et al., 2010, Foster and Foster-Hunter, 2011, 
Czerkas, 1994). Diplodocid integument fossils in particular are only known from several small skin impressions and carbon film fossils consisting of the patterns described above. The most noteworthy diplodocid integument discovered are the dorsal spines found near the caudal region of a diplodocid in the Morrison Formation, as this discovery shed light on the potential integument diversity and the appearance of dinosaurs (Czerkas, 1992). New fossilized skin from Diplodocus sp has recently been discovered at the Mother's Day Quarry in Montana. Some of the first skin fossils discovered at this quarry exhibited polygonal scales (Myers and Storrs, 2007, Storrs, Oser \& Aull, 2012). However, information on these scale impressions is limited as in those previous studies, the skin impressions were primarily mentioned only as evidence for taphonomic interpretations, rather than descriptive analyses of the scale patterns and characteristics themselves. In this paper, we describe newly discovered Diplodocus sp. carbonaceous skin from the Mother's Day Quarry that consist of new scale shapes and patterns never before seen in diplodocids.

\section{Site Background}

The Mother's Day Quarry, located in the Bighorn Basin, Montana, consists of Upper Jurassic deposits. The quarry has yielded over 2,500 fossils over the past two decades belonging to at least fifteen different Diplodocus individuals of a single indeterminate species (Myers and Storrs, 2007). Originally, the Diplodocus specimens were classified as "juveniles" and "subadults" due to their small size and unfused bones (Myers and Storrs, 2007, Storrs et al., 2012, Woodruff and Fowler, 2012). However, more recent analyses revealed that some of these individuals may be more histologically mature than previously thought, indicating there may be an additional dwarfed morphotype present in the Mother's Day Quarry (Woodruff et al., 2018). Only two other taxa have been discovered at this site as represented by allosaur teeth and a single crustacean. The proposed reason this site contains mostly Diplodocus is that these individuals may have lived in a herd together, showing gregarious behavior (Myers and Fiorillo, 2009). Sedimentological and taphonomic evidence suggests that the Diplodocus skeletons are the result of a single mass mortality event, probably due to drought, followed by transportation and deposition in a high-density debris flow (Storrs, Oser \& Aull, 2012).

\section{Skin Preservation}

Based off physical evidence and what is known of other Morrison diplodocid integument fossils, it can be inferred that the skin is preserved as a carbonaceous film rather than an impression or mold. Diplodocus sp skin has been found previously from the Mother's Day Quarry and has also been confirmed to be preserved as carbonaceous film (Storrs, Oser \& Aull, 2012), so it would make sense for this skin to also be preserved as a carbonaceous film. The preservation of the skin was most likely due to anoxic conditions of the burial preventing the skin from decaying as evidenced by the presence of calcareous rinds on some of the long bones in the quarry (Myers and Storrs, 2007). As discussed by Foster and Foster-Hunter (2011), wet anoxic conditions allow for the preservation of soft biological material in the form of carbon, which is commonly seen in 
fossilized plants but can also occur with dinosaur skin. In addition to anoxic conditions, the skin would have gone through a period of desiccation before being buried by the debris flow, which also aided in preservation as this would have toughened the skin and allowed it to survive for longer than other soft tissues (Storrs et al, 2012). The integument is preserved as a 3-dimensional relief and differs in coloration from the surrounding matrix, exhibiting grey, dark brown, or black coloration as appose to the yellow and red of the surrounding siltstone. On some of the scale surfaces, there is a bumpy texture that can be described as multiple small "tubercles" inside the larger scales. These small "tubercles" are most likely dermal papillae and are the result of degradation of the epidermis revealing the dermis underneath (Czerkas, 1994). Dermal papillae are a common presence in carbonaceous sauropod skin fossils (Czerkas, 1994, Foster and FosterHunter, 2011), but unlike other carbonaceous sauropod skin, the dermal papillae in this specimen are not as prominent and are only present on some scales. This could indicate that the epidermis is preserved on some areas of the skin. The distinct coloration, presence of dermal papillae, and preservation in anoxic conditions gives evidence that this is the fossilized skin itself preserved as a carbonaceous film, rather than an impression.

\section{Materials and Methods}

The fossilized skin, designated MDS-2019-028, is still in situ but excavation is planned for July 2021. The skin was found in proximity to two dorsal ribs also in situ: MDS-2019-009 and MDS2019-010, though it is unknown whether the skin and ribs belonged to the same individual based on preservation. The current plan for excavation is that first photogrammetry will be done on the skin, so in case the skin becomes damaged during transportation, we will still have a replica. The skin will be deposited first at the Academy of Natural Sciences in Philadelphia, where it will be prepared. After preparation of the skin is complete, it will then be sent to the collections at the Cincinnati Museum Center. The ribs will follow the same plan. Permits from the United States Department of the Interior Bureau of Land Management (permit numbers: MTM 109606, MTM 109606-e1, MTM 109606-e2, MTM 109606-e3, MTM 109606-e4) were issued to co-authors Jason Schein and Jason Poole in order to allow for excavation of fossils. A quarry map has yet to be made but locations of all fossils have been recorded with a surveyor's transit. Instead, we are utilizing an older quarry map to indicate the location of the skin and ribs (Fig.1). All other pictures, drawings, and figures were created by Tess Gallagher.

To make description of the skin easier and to keep track of where the different scale shapes are in relation to one another, different areas of the skin have been designated as fragments identified with capital letters such as A, B, C (Fig. 2). On fragments A and B, sections of the skin that change in scale shape have been designated with lower case letters such as Aa, Ab, etc. Fragment $\mathrm{C}$ receives no such formatting since it lacks the scale diversity as seen on the other two fragments. Although it cannot be said with certainty where the skin belongs on the body, body area terminology will be used in quotation marks. Section Ab is designated as representing 
119

120

121

122

123

124

125

126

127

128

129

130

131

132

133

134

135

136

137

138

139

140

141

142

143

144

145

146

147

148

149

150

151

152

153

154

155

156

157

158

"ventral" (Fig. 3) while fragment B is designated as "anterior" (Fig.2.) to all other areas of the integument.

\section{Descriptions}

The integument consists of non-overlapping scales, or tubercles, similar to those observed on other dinosaur skin fossils (e.g., Arbour et al., 2014, Bell, 2014, Christiansen and Tschopp, 2010, Czerkas,1994, Czerkas SA and Czerkas SJ, 1997, Kim et al., 2010). There is integument on both sides of the rib MDS-2019-010 (Fig. 1). The rib itself continues into the hill while the skin extends on the bedding plane surface. Although the skin and ribs were found in close proximity to each other, there are several variables that bring into question whether they belonged to the same individual. For one, the skin fossils are believed to be the skin itself, preserved as a carbonaceous film. It would be expected to see the skin preserved over the rib itself since the scales are positioned how they would be in life, preserved in a 3-dimensional relief. Instead, it appears that the skin goes underneath the rib on the bedding plane. It should also be noted that the skin fossil has more scale diversity then would be expected in such a small area, especially when compared to the size the individual from which the rib originated. Although it's not impossible for a Diplodocus of this individual's size to have so much scale diversity, it would certainly be unexpected for reasons further discussed later in the paper. Despite the uncertainty of the relationship with the rib, the skin can still be attributed to the genus Diplodocus. One of the defining features of the Mother's Day Quarry is the overwhelming abundance of Diplodocus material. Not only are there no other dinosaur taxa present other than the presence of Allosaurus teeth, which were most likely preserved from the result of scavenging, but even other nondinosaur taxa such as turtles, crocodilians, etc. are completely absent from the quarry other than the presence of a single crustacean. Although it is possible there is non-Diplodocus fossil material at the quarry that has yet to be uncovered, Diplodocus would still be the most prominent taxon of the Mother's Day Quarry, making Diplodocus sp the most likely identity of the skin. The integument exhibits six different scale shapes, four of which being newly described on this specimen. The scales shapes are listed as follows:

1. Polygonal: the most common scale shape located in three different areas on the integument. Polygonal scales located "dorsally" are larger at $5 \mathrm{~mm}$, while "ventral" polygonal scales are consistently $<5 \mathrm{~mm}$.

2. Pebble: the smallest of the scales at $1-2 \mathrm{~mm}$, located "ventrally" alongside small polygonal scales.

3. Rectangular: scales that vary in length and overall size depending on placement, reaching between 2-10 mm. These scales are found abruptly cutting off the "ventral" polygonal scales, as appose to naturally transitioning in shape.

4. Globular: irregularly shaped scales that lack defined angles or consistent patterning. They exhibit a more prominent 3-dimensional relief then compared to the other scales except for the ovoid and dome scales. These scales measure 5-10 mm in diameter. 
5. Ovoid: the consistently largest scales on the integument, measuring $10 \mathrm{~mm}$ in length. These scales are found clustered together, with the pointed ends of the ovoid pointing in the same direction, and also have a more prominent 3-Dimensional relief than the rest of the scales. These scales also abruptly interrupt nearby polygonal scales.

6. Dome: two scales located several centimeters in front of the ovoid cluster of differing sizes. The larger scale is $5 \mathrm{~mm}$ while the smaller scale is $<5 \mathrm{~mm}$, and both exhibit prominent 3-Dimensional relief similar to the ovoid scales.

The first and biggest fragment found measures about $240 \mathrm{~mm}$ in "dorsoventral" height and 600 $\mathrm{mm}$ in "anteroposterior" width (Fig.2. A). This skin appears to go underneath the rib, and might have originally been connected to fragment $\mathrm{B}$, based on the similar scale size in both fragments. Fragment B is located "anterior" to fragment A (Fig.2) and consists of three fragmented integument that range between $20-130 \mathrm{~mm}$ in "dorsoventral" height and $10-40 \mathrm{~mm}$ in "anteroposterior" width. Fragment C is located "dorsally" to fragment A and is the most "dorsally" located fragment. Fragment $\mathrm{C}$ consists of multiple small fragments that range in size from 20-100 mm in "dorsoventral" height and 20-50 $\mathrm{mm}$ in "anteroposterior" width. Considering how close fragment $\mathrm{C}$ is to fragment $\mathrm{A}$ as well as fragment $\mathrm{C}$ sharing similarly sized and shaped scales to fragment $\mathrm{A}$, fragment $\mathrm{C}$ was most likely once connected to fragment $\mathrm{A}$.

\section{Fragment A}

Fragment A contains signature pebble and polygonal scales on its lower region (designated Ab in Fig.3) which measure less than $5 \mathrm{~mm}$. These are similar in shape to scales observed in other diplodocid skin fossils as described by Czerkas (1992). To the right of section Ab, the scales lose definition inside of two oblong shaped impressions in the skin itself that measure roughly $40 \mathrm{~mm}$ in length (Fig.3). The current hypothesis is that this formation may represent a small dinosaur footprint, as this is the only area where the scales become non discernable, and the consistency of the oblong shapes mimic the look of other known dinosaur footprints, with what could be interpreted as individual toe pads present. However, it is also possible this formation could have been caused by other taphonomic processes, such as wrinkling of the integument created during burial. If these impressions do represent a footprint, the footprint would have most likely been made while the skin was desiccating, before it was buried in a debris flow. To the farthest left of section $\mathrm{Ab}$, the scales are even smaller in size $(\sim 1 \mathrm{~mm})$ and may correspond to the small scales in section $\mathrm{B}$. The scales change shape from small pebble and polygonal scales at the lower region of $\mathrm{Ab}$ into rectangular shaped tubercles in the upper region designated Aa. In section Aa, rectangular scales are visible ranging in size from $\sim 5 \mathrm{~mm}$ to $\sim 10 \mathrm{~mm}$ (Fig.3). The scales in section Aa change from minuscule $\sim 1 \mathrm{~mm}$ scales to the larger rectangle tubercles from right to left of the picture (see Fig.3 and 4) and change into polygonal scales at the top (Fig.4). Rectangular scales have been observed before in sauropods, most notably in embryonic titanosaur scales from Patagonia (Coria and Chiappe, 2007). However, the rectangular scales of the titanosaur fetuses are neatly lined up and overlap each other. In addition, these rectangular scales observed in the Patagonian fetuses are much larger than the surrounding scales. The rectangular tubercles on the Diplodocus specimen instead do not display such a specific pattern, showing multiple rows of straightly aligned rectangular and square scales. These rectangular 
200

201

202

203

204

205

206

207

208

209

210

211

212

213

214

215

216

217

218

219

220

221

222

223

224

225

226

227

228

229

230

231

232

233

234

235

236

237

238

239

scales then transition into more polygonal scales in section Ac that are around $5 \mathrm{~mm}$ in diameter. The polygonal scales transition into smooth ovoid scales in section Ad measuring less than $\sim 10 \mathrm{~mm}$ in length and are also more raised than the other surrounding scales (Fig.5). These scales are closely clustered together, and all oriented similarly; the pointed ends of the scales pointing towards section Ac. This cluster measures roughly $30 \mathrm{~mm}$ by $70 \mathrm{~mm}$. Between the cluster of ovoid scales and the polygonal scales of section Ac, there are two smaller tubercles that are slightly raised and smooth in texture but are instead domed rather than ovoid (Fig.6). They are located a few centimeters in front of the oval scale cluster, exhibiting no clear organized scale pattern. In addition to the dense cluster of ovoid tubercles, section Ad also displays another curious arrangement of scales. At the forefront of the cluster of ovoid scales, where the ovoid scales meet the polygonal scales, there is an arrangement of five ovoid scales in an arrow-like shape pointing towards section Ac. The arrow orientation consists of a single scale at the point and two scales on each side. The ovoid scales look similar in nature and orientation to scales seen dorsally on modern day reptiles. Also taking into consideration the possible existence of dorsal spines on diplodocids (Czerkas, 1992), these ovoid scales may be homologous and may have also been present on the dorsal side of the animal, though whether these ovoid scales would have eventually grown into dorsal spines or kept their shape throughout life is up to debate.

\section{Fragment B}

Skin fragment B (Fig.7) shows similar sized scales to fragment A but exhibits a different scale orientation "ventrally" as well as a different scale shape "dorsally". Scales in fragment Ba are similar in size to those observed in fragment Aa but are irregular in shape with bean and globular-shaped tubercles arranged in a puzzle-like formation, often seen 'hugging' or folding over nearby tubercles of similar shape (Fig.8). The scales also display more rounded edges compared to the tubercles observed in fragment A, and have deeper, more visible indentations inbetween each scale. Section $\mathrm{Bb}$ consists of square and polygonal scales, with sizes comparable to $\mathrm{Ab}$. An interesting feature in section $\mathrm{Bb}$ is that the small square scales are organized in linear rows that arch downwards, interrupting the nearby polygonal scale patterning (Fig.8). There are at least two additional rows of arching scales next to the row closest to the polygonal scales. This patterning is very similar to scale patterning seen around crocodilian limbs (Fig.9), which may suggest that this section may have been from a limb region in life. Skin section Bc consists of small $<5 \mathrm{~mm}$ pebble-like scales.

\section{Fragment C}

Fragment C (Fig.10) consists of multiple small pieces of skin. The scales range in size from 2 $\mathrm{mm}$ to $5 \mathrm{~mm}$. The scales appear to change in size depending upon their location: fragments closer to section Ad are smaller than those closest to Ac. The fragments exhibit the same polygonal scales seen on section Ac and are also close in proximity and lay on the same bedding plane, so it can be assumed that these fragments were at one point attached to fragment $\mathrm{A}$.

\section{Discussion}

Through close examination of the integument, the evidence suggests that the skin belonged to a small individual, possibly of "juvenile" or even infantile maturation. The evidence 
240 we used to come to this conclusion is the presence of small, potentially "juvenile" bones in the

241

242

243

244

245

246

247

248

249

250

251

252

253

254

255

256

257

258

259

260

261

262

263

264

265

266

267

268

269

270

271

272

273

274

275

276

277

278

279

280

281

282
Mother's Day Quarry, the significant diversity of scale shapes over a small area of the integument, the small size of the scales, and the orientation of the scales implying the presence of a small limb. Each of these pieces of evidence is further discussed below.

The presence of young and small individuals from this quarry have been thoroughly reported between 38-75\% the size of other known adult Diplodocus specimens. Woodruff et al. (2018) even reported to have found the smallest Diplodocus skull ever uncovered. Therefore, it is not unexpected that skin fossils found in the same bonebed are from a small and potentially young individual. However, it should be noted that there is still much debate on the maturational status of the Mother's Day Quarry Diplodocus. Although there is evidence present at the Mother's Day Quarry that the Diplodocus were "juvenile", some of the elements used to determine maturational status have been brought into question. For instance, increase in neural spine bifurcation was originally thought to be a key characteristic in diplodocid ontogeny (Woodruff and Fowler, 2012). However, other studies have shown that variation in sauropod vertebra can mimic ontogenetic features and are thus not reliable in determining maturational status (Wedel and Taylor, 2013). Although we do believe the fossilized skin belongs to a small and potentially "juvenile" individual, we must stress that there is still much debate surrounding the maturational status of the Mother's Day Quarry Diplodocus, and that more research is required in order to determine if the individuals are of adult or juvenile status. The integument represents a relatively small area in comparison to the overall body size of what would be an adult Diplodocus sp. Despite this, the integument shows a significant diversity of scale shapes and orientations especially when compared to other known Morrison diplodocid integument fossils. All other examples of diplodocid integument from the Morrison formation, minus the possible Kaatadocus dorsal spines, have only ever exhibited polygonal or hexagonal scales (Czerkas, 1994, Foster and Foster-Hunter, 2011, Myers and Storrs, 2007). Change in scale shape across integument is usually indicative of a transition from one body part to another, as evidenced by modern reptiles and other dinosaur taxa. The theropod Juraventator exhibits three distinct scale shapes on its tail, of which the scale shape varies based on whether it is dorsally or ventrally located. Specifically, the scale shapes change ventral to dorsal in the following order: scutate ventral scales, ornamental scales, tuberculate scales, and finally feathers at the most dorsal part of the tail (Bell and Hendrickx, 2020). MDS-20019-028 shows a similar transition, featuring up to six different scale shapes localized on different areas of the integument that change in a "dorsoventral" and "anteroposterior" manner (Fig.11). Such scale diversity has also been documented in the past for sauropods, specifically in titanosaur embryos. The skin of these titanosaur embryos exhibits six different scale arrangements consisting of various scale shapes, including parallel rows of large tubercles, striatelike rows, etc (Coria and Chiappe, 2007). Although exact location of these scale arrangements on the body is unknown, the diversity in scale shapes and orientations on these specimens are indicative of differing areas of placement on the body. The reason why these embryos have such scale diversity preserved is most likely due to their size. Specifically, a greater area of integument relative to the body is more likely to preserve in a smaller sauropod versus a large, full-grown sauropod. This could be the reason for why MDS-2019-028 expresses more scale diversity compared to other diplodocid integument fossils. In addition to the diverse orientation of the scales, the polygonal scales described on

Peer) reviewing PDF | (2020:12:55937:2:0:NEW 23 Feb 2021) 
283

284

285

286

287

288

289

290

291

292

293

294

295

296

297

298

299

300

301

302

303

304

305

306

307

308

309

310

311

312

313

314

315

316

317

318

319

320

321

322

323

324

325

MDS-2019-028 are much smaller than other known diplodocid polygonal scale fossils. For example, the biggest polygonal scales found during the reopening of the Howe Quarry in 1990 reach $30 \mathrm{~mm}$ in size (Czerkas, 1994, Tschopp et al., 2020), apatosaurine diplodocid polygonal scales from Mygatt-Moore Quarry have an average diameter of 25mm (Foster and Hunt-Foster, 2011), and previously discovered Diplodocus sp polygonal scales from the Mother's Day Quarry measure 10mm (Myers and Storrs, 2007). None of the polygonal scales observed in MDS20019-028 exceed $5 \mathrm{~mm}$ in size, making the biggest of these polygonal scales six times smaller than the biggest recorded diplodocid polygonal scales and half the size of other Mother's Day polygonal scales. Furthermore, the Mygatt-Moore apatosaurine scales were found in association with large Apatosaurus material, which indicates that $30 \mathrm{~mm}$ polygonal scales are a distinctive trait of larger sized diplodocids. In terms of both scale size and orientation, another comparison can be made to the fossilized skin of the non-diplodocid sauropod Tehuelchesaurus. The polygonal scales of Tehuelchesaurus greatly vary in size measuring between $1 \mathrm{~mm}$ to $30 \mathrm{~mm}$ in diameter (Gimenez, 2007). Although the presence of small scales on a big sized sauropod may bring into question the reliability of comparing scale sizes between MDS-2019-028 and other diplodocids as evidence of small body size, the Tehuelchesaurus integument can also be used in favor of this argument since the scale sizes greatly differ depending on where they are located on the body. Gimenez (2007) inferred that the scales varied in size depending on whether they were ventrally or dorsally located; scale impressions associated with the arms and thoracic region were $1-3 \mathrm{~mm}$ in diameter, while scales associated with the scapula were $30 \mathrm{~mm}$ in diameter. MDS-2019-028 has several sections composed of polygonal scales which vary in size depending on whether they are "ventrally" or "dorsally" located. Specifically, polygonal scales from section $\mathrm{Ab}$ and $\mathrm{Bb}$ are consistently less then $5 \mathrm{~mm}$ while polygonal scales in section $\mathrm{Ac}, \mathrm{Ad}$, and most of fragment $\mathrm{C}$ are equal to $5 \mathrm{~mm}$. Other than the polygonal scales on MDS-2019-028, there seems to be a general trend in the size of all the scales based on location, since the majority of the small scales are located "ventrally" while all the biggest scales are located "dorsally" (Fig.12). The high diversity of scales over a small area potentially being indicative of change in body area, combined with the small size of the polygonal scales compared to other Morrison diplodocid polygonal scales, and the similarity in distribution of small and large sized scales like seen in Tehuelchesaurus, suggests that MDS-2019-028 belongs to a small individual.

The scales on section $\mathrm{Bb}$ curve downward at an extreme angle of $66^{\circ}$ relative to the square scales closest to the polygonal scales. This type of patterning is often seen on crocodilians, arching around the area where the limbs attach to the body such as the shoulder and waist. Though there is no direct evidence of arching scale rows around the limbs of dinosaurs, it has been noted that in exceptionally well preserved hadrosaur "mummies" such as those of the genus Edmontosaurus and Corythosaurus, the scales are smallest around the limb regions to accommodate for flexibility (Brown, 1916, Osborn,1912). It is, therefore, possible that the scales in section $\mathrm{Bb}$ may have had the same purpose, and most likely surrounded a limb. As discussed previously, the polygonal scales on the arm of Tehuelchesaurus were of similar size to the polygonal scales from the thoracic region (Gimenez, 2007). The polygonal scales on section $\mathrm{Bb}$ are of similar small size as the polygonal scales from section $\mathrm{Ab}$, which is consistent with what we currently know of scale size distribution in sauropods if we are to consider section $\mathrm{Bb}$ a limb region and section $\mathrm{Ab}$ a thoracic region. If true that section $\mathrm{Bb}$ belonged to a limb, the limb in 
326

327

328

329

330

331

332

333

334

335

336

337

338

339

340

341

342

343

344

345

346

347

348

349

350

351

352

353

354

355

356

357

358

359

360

361

362

question would have been relatively small, considering the shoulder/leg would be no wider than $100 \mathrm{~mm}$ (Fig.2). Despite the evidence, it should be noted that we cannot rule out the possibility that the rib and the skin belonged to the same individual. Although the integument appears to go under the rib on the bedding plain, it is also possible that the integument was originally over the rib but either eroded away or was removed by accident. Additionally, as stated above, the presence of small 1-3mm scales on Tehuelchesaurus bring into question of whether the small scales in MDS-2019-028 indicate small size. It's possible that the ventral scales of Diplodocus were larger in general compared to overall body size to the ventral scales of Tehuelchesaurus, or that the small ventral scales in large sauropods are a result of negative allometry. More research is required to understand the full extent of diplodocid integument, and how it may differ in size and distribution in individuals of different sizes. However, we still find the following evidence worth discussing, as it opens discussion on how integument can be used to determine more than just a dinosaur's appearance, but also to indicate an individual's size and determining location of the integument on the body without skeletal material present.

\section{Conclusion}

The skin (MDS-2019-028) discovered at the Mother's Day Quarry shows new scale shapes and orientations never before seen in Diplodocus sp, including rectangular, globular, and ovoid scales as well as the arching scale rows orientation. Scale diversity and orientation on this small patch of integument strongly suggests the skin belonged to a very small individual and potentially a "juvenile". If this can be confirmed, MDS-2019-028 may provide information on the ontogenetic development of diplodocid scales. We would also like to compare MDS-2019028 to other Diplodocus sp skin fossils from the Mother's Day Quarry for future studies into diplodocid integument. More research can also be conducted in the taphonomic reasons why diplodocid skin is more commonly preserved as carbonaceous film rather than impressions in the Morrison formation. This discovery also highlights the scientific significance of the Mother's Day Quarry and the potential to find additional skin fossils during future excavations.

\section{Acknowledgements}

The authors thank Lisa Marshall for help in the field, as well as the Bighorn Basin Paleontological Institute for heading the exhibition, Mia Roberts for help with editing, Dr. Barbara Patel (Union College) for feedback on scale interpretations and for access of the alligator specimen, and Dr. Anouk Verheyden (Union College) for help writing the manuscript.

\section{References}


363

364

365

366

367

368

369

370

371

372

373

374

375

376

377

378

379

380

381

382

383

384

385

386

387

388

389

390

391

392

393

394

395

396

397

Arbour, V.M., Burns, M.E., Bell, P.R. and Currie, P.J., 2014. Epidermal and dermal integumentary structures of ankylosaurian dinosaurs. Journal of Morphology, 275(1), pp.39-50.

Bell, P.R., 2014. A review of hadrosaurid skin impressions. Hadrosaurs, pp.572-590.

Bell, P.R. and Hendrickx, C., 2020. Epidermal complexity in the theropod dinosaur Juravenator from the Upper Jurassic of Germany. Palaeontology.

Brown, B., 1916. Corythosaurus casuarius: skeleton, musculature and epidermis. order of the Trustees, American Museum of Natural History.

Brown, C.M., Henderson, D.M., Vinther, J., Fletcher, I., Sistiaga, A., Herrera, J. and Summons, R.E., 2017. An exceptionally preserved three-dimensional armored dinosaur reveals insights into coloration and Cretaceous predator-prey dynamics. Current Biology, 27(16), pp.2514-2521.

Chiappe, L.M., Coria, R.A., Dingus, L., Jackson, F., Chinsamy, A. and Fox, M., 1998. Sauropod dinosaur embryos from the Late Cretaceous of Patagonia. Nature, 396(6708), pp.258-261.

Christiansen, N.A. and Tschopp, E., 2010. Exceptional stegosaur integument impressions from the Upper Jurassic Morrison Formation of Wyoming. Swiss Journal of Geosciences, 103(2), pp.163-171.

Coria, R.A. and Chiappe, L.M., 2007. Embryonic skin from Late Cretaceous sauropods (Dinosauria) of Auca Mahuevo, Patagonia, Argentina. Journal of Paleontology, 81(6), pp. 15281532.

Czerkas, S.A., 1992. Discovery of dermal spines reveals a new look for sauropod dinosaurs. Geology, 20(12), pp.1068-1070

Czerkas, S.A., 1994. The history and interpretation of sauropod skin impressions. Gaia, 10, pp.173-182.

Czerkas, Stephen A.; Czerkas, Sylvia J. (1997). "The Integument and Life Restoration of Carnotaurus". In Wolberg, D. I.; Stump, E.; Rosenberg, G. D. (eds.). Dinofest International. Academy of Natural Sciences, Philadelphia. pp. 155-158.

Del Valle Giménez, O., 2007. Skin impressions of Tehuelchesaurus (Sauropoda) from the Upper Jurassic of Patagonia. Revista del Museo Argentino de Ciencias Naturales nueva serie, 9(2), pp.119-124.

Foster, J.R. and Hunt-Foster, R.K., 2011. New occurrences of dinosaur skin of two types (Sauropoda? and Dinosauria indet.) from the Late Jurassic of North America (Mygatt-Moore Quarry, Morrison Formation). Journal of Vertebrate Paleontology, 31(3), pp.717-721.

Kim, J.Y., Kim, K.S., Lockley, M.G. and Seo, S.J., 2010. Dinosaur skin impressions from the Cretaceous of Korea: new insights into modes of preservation. Palaeogeography, Palaeoclimatology, Palaeoecology, 293(1-2), pp.167-174. 
398 Myers, T.S. and Storrs, G.W., 2007. Taphonomy of the Mother's Day Quarry, Upper Jurassic Morrison Formation, south-central Montana, USA. Palaios, 22(6), pp.651-666.

400 Myers, T.S. and Fiorillo, A.R., 2009. Evidence for gregarious behavior and age segregation in 401 sauropod dinosaurs. Palaeogeography, Palaeoclimatology, Palaeoecology, 274(1-2), pp.96-104.

402 Osborn, H.F., 1912. Integument of the iguanodont dinosaur Trachodon.

403 Platt, B.F. and Hasiotis, S.T., 2006. Newly discovered sauropod dinosaur tracks with skin and 404 foot-pad impressions from the Upper Jurassic Morrison Formation, Bighorn Basin, Wyoming, 405 USA. Palaios, 21(3), pp.249-261.

406 Schein, J.P, Poole, J.C., Schmidt, R.W. and Rooney, L., 2019. Reopening the Mother's Day 407 Quarry (Jurassic Morrison Formation, Montana) is yielding new information. Geological Society 408 of America - Annual Meeting, Arizona Sep 22-25 2019.

409 Storrs, G.W., Oser, S.E. and Aull, M., 2013. Further analysis of a Late Jurassic dinosaur bone410 bed from the Morrison Formation of Montana, USA, with a computed three dimensional 411 reconstruction. Earth and Environmental Science Transactions of the Royal Society of 412 Edinburgh, 103(3-4), pp.443-458.

413 Tschopp, E., Mehling, C. and Norell, M.A., 2020. Reconstructing the specimens and history of 414 Howe Quarry (Upper Jurassic Morrison Formation; Wyoming). American Museum Novitates, 415 2020(3956), pp.1-56.

416 Wedel, M.J. and Taylor, M.P., 2013. Neural spine bifurcation in sauropod dinosaurs of the 417 Morrison Formation: ontogenetic and phylogenetic implications. PalArch's Journal of Vertebrate 418 Palaeontology, 10(1), pp.01-34.

419 Woodruff, D.C. and Fowler, D.W., 2012. Ontogenetic influence on neural spine bifurcation in 420 Diplodocoidea (Dinosauria: Sauropoda): a critical phylogenetic character. Journal of 421 Morphology, 273(7), pp.754-764.

422 Woodruff, D.C., Carr, T.D., Storrs, G.W., Waskow, K., Scannella, J.B., Nordén, K.K. and 423 Wilson, J.P., 2018. The smallest diplodocid skull reveals cranial ontogeny and growth-related 424 dietary changes in the largest dinosaurs. Scientific reports, 8(1), pp.1-12.

425 Xu, X., Wang, K., Zhang, K., Ma, Q., Xing, L., Sullivan, C., Hu, D., Cheng, S. and Wang, S., 426 2012. A gigantic feathered dinosaur from the Lower Cretaceous of China. Nature, 484(7392), 427 pp.92-95. 
Figure 1

Quarry map of the Mothers Day site showing bone location.

Red circle indicates approximate location of skin and rib fossils. Quarry map modified from Myers and Storrs, 2007. Permission was granted from the Society of Sedimentary Geology for use of this figure.

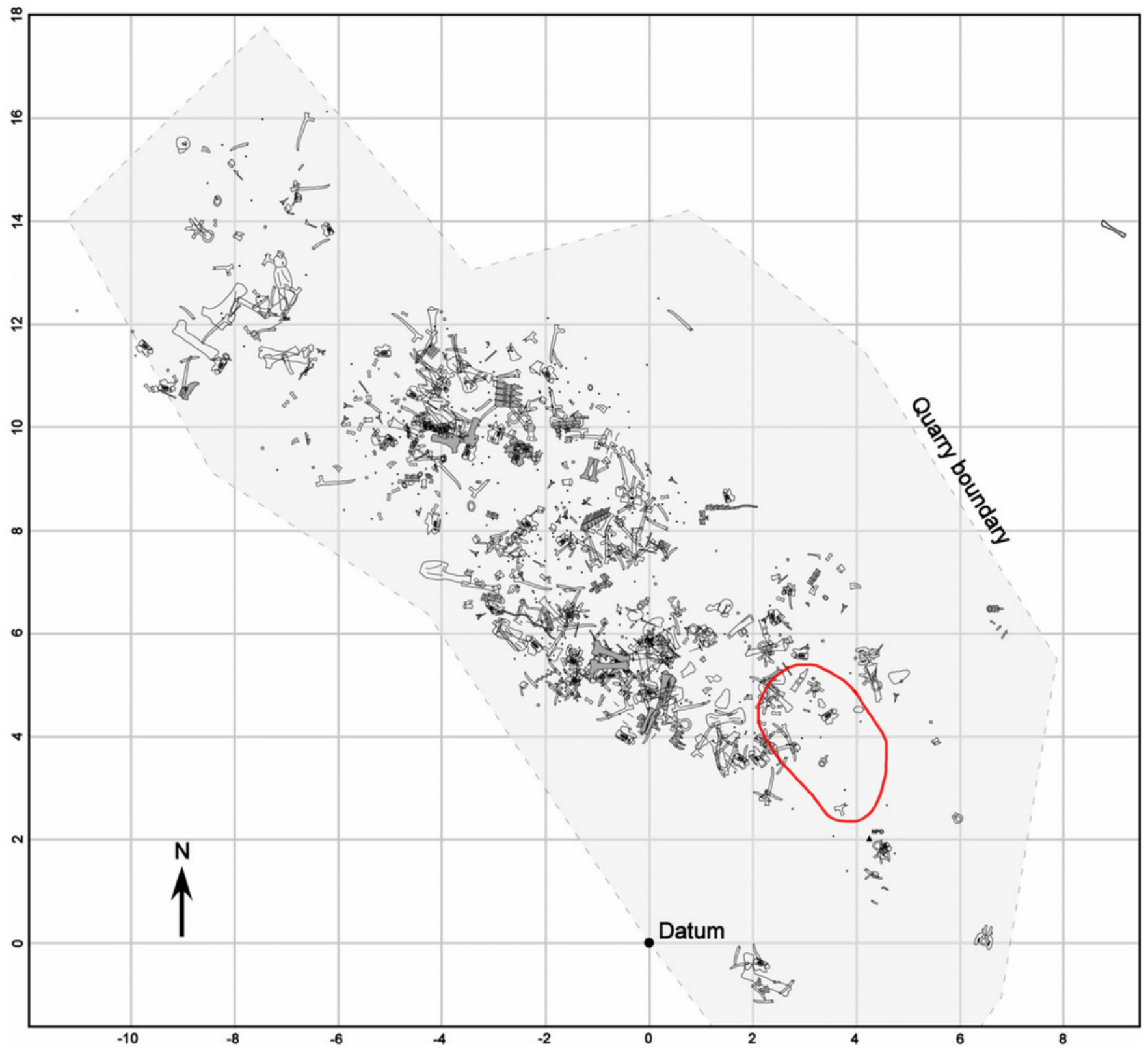




\section{Figure 2}

Diplodocus sp skin molds in association with the two ribs.

(A) the first and largest of the molds found; showcases various scale shapes and patterns including the never before seen rectangular tubercles as well as the convex oval shaped tubercles. (B) Skin fragments on the left side of the rib that most likely connect to $A$. The fragment consists of tubercles of various shapes, the biggest of which are smooth in texture and are approximately $\sim 10 \mathrm{~mm}$ in length. The other scales are smaller but vary in shape. They also appear to show a change in scale orientation. (C) Skin fragments that were most likely once connected to fragment $A$. These scales are located in a matrix of rock above $A$. Scale shapes include tiny $\sim 1 \mathrm{~mm}$ tubercles and larger $\sim 10 \mathrm{~mm}$ polygonal tubercles. The tape measure indicates the scale in centimeters. 


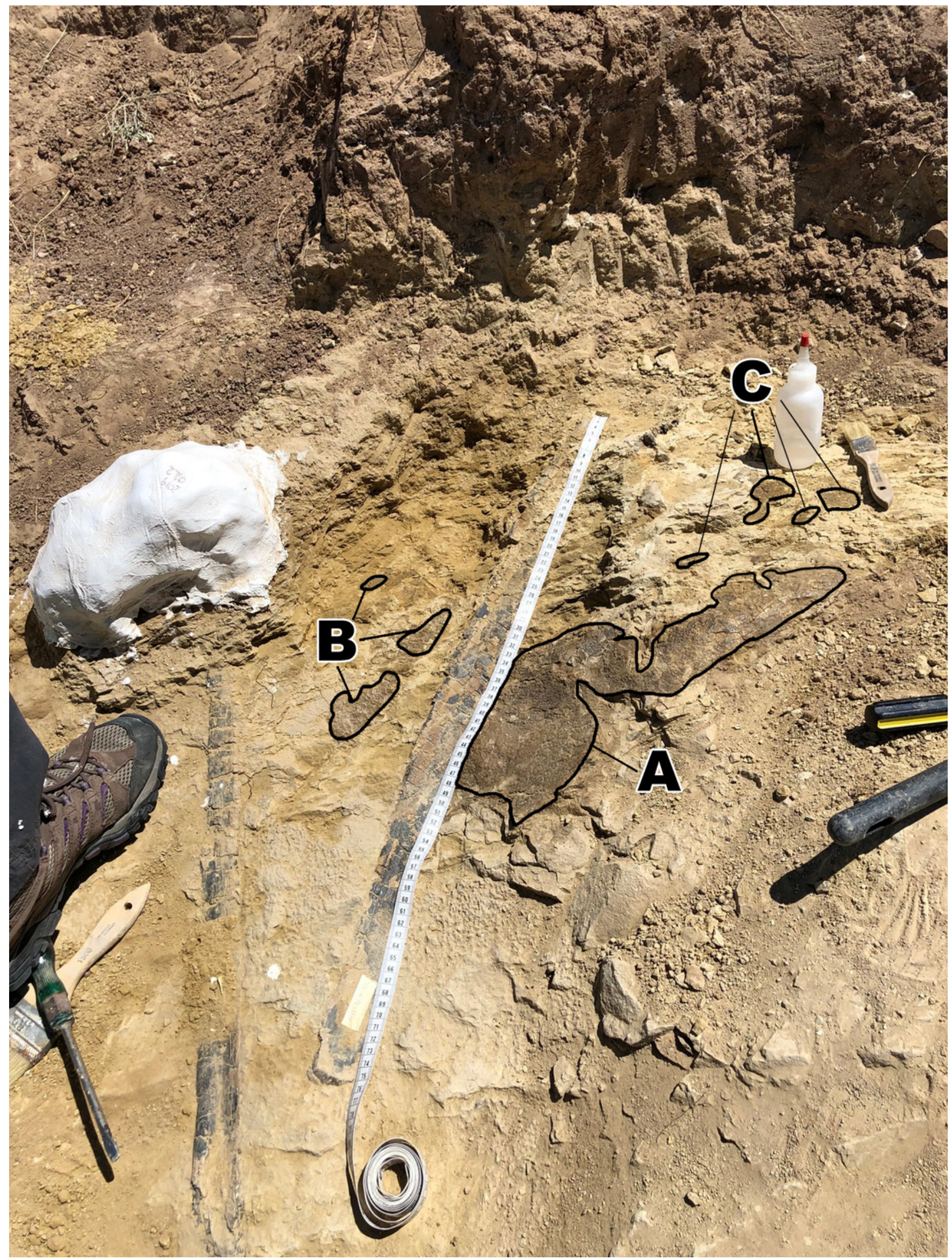


Figure 3

Close up of the largest area of skin fragment A with labeled sections of change in scale shape.

(Aa) Rectangular tubercles that range between $\sim 5 \mathrm{~mm}$ to $\sim 10 \mathrm{~mm}$. (Ab) Small polygonal tubercles that range in sizes of around $\sim 5 \mathrm{~mm}$ as well as small pebble tubercles of about $\sim 2$ $\mathrm{mm}$ in size located to the left of the picture. (Ac) Larger polygonal tubercles of similar size to the rectangular tubercles. Scale in $\mathrm{cm}$. 


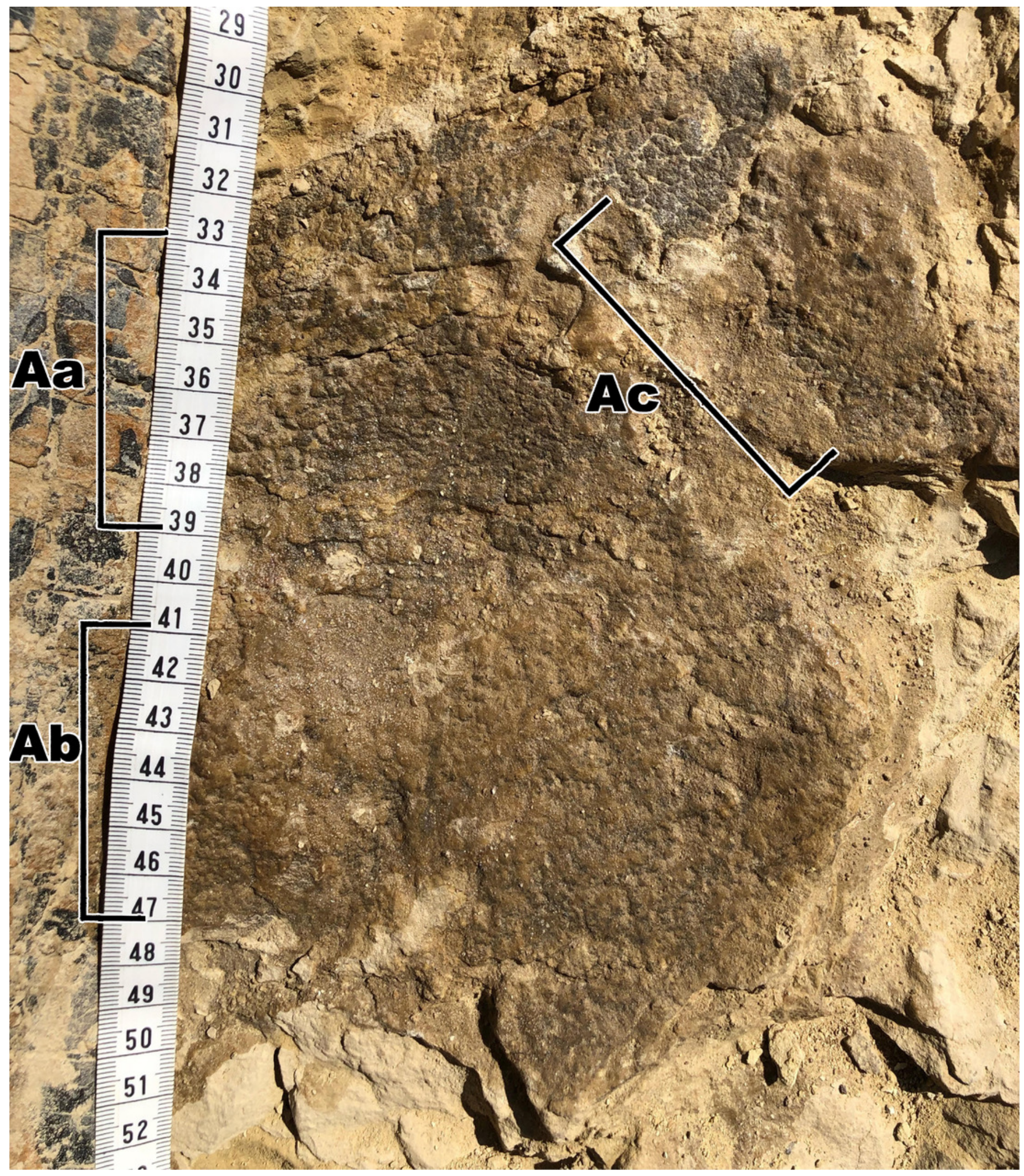


Figure 4

Section Aa exhibiting rectangular tubercles and possible footprint from section Ab with drawings for clarity.

(A) Close up picture of section Aa. (B) Interpretive drawing of section Aa to help distinguish individual rectangular tubercles. (C) Close up picture of possible footprint from section Ab. (D) Interpretive drawing of footprint impression. Drawings by TG. 


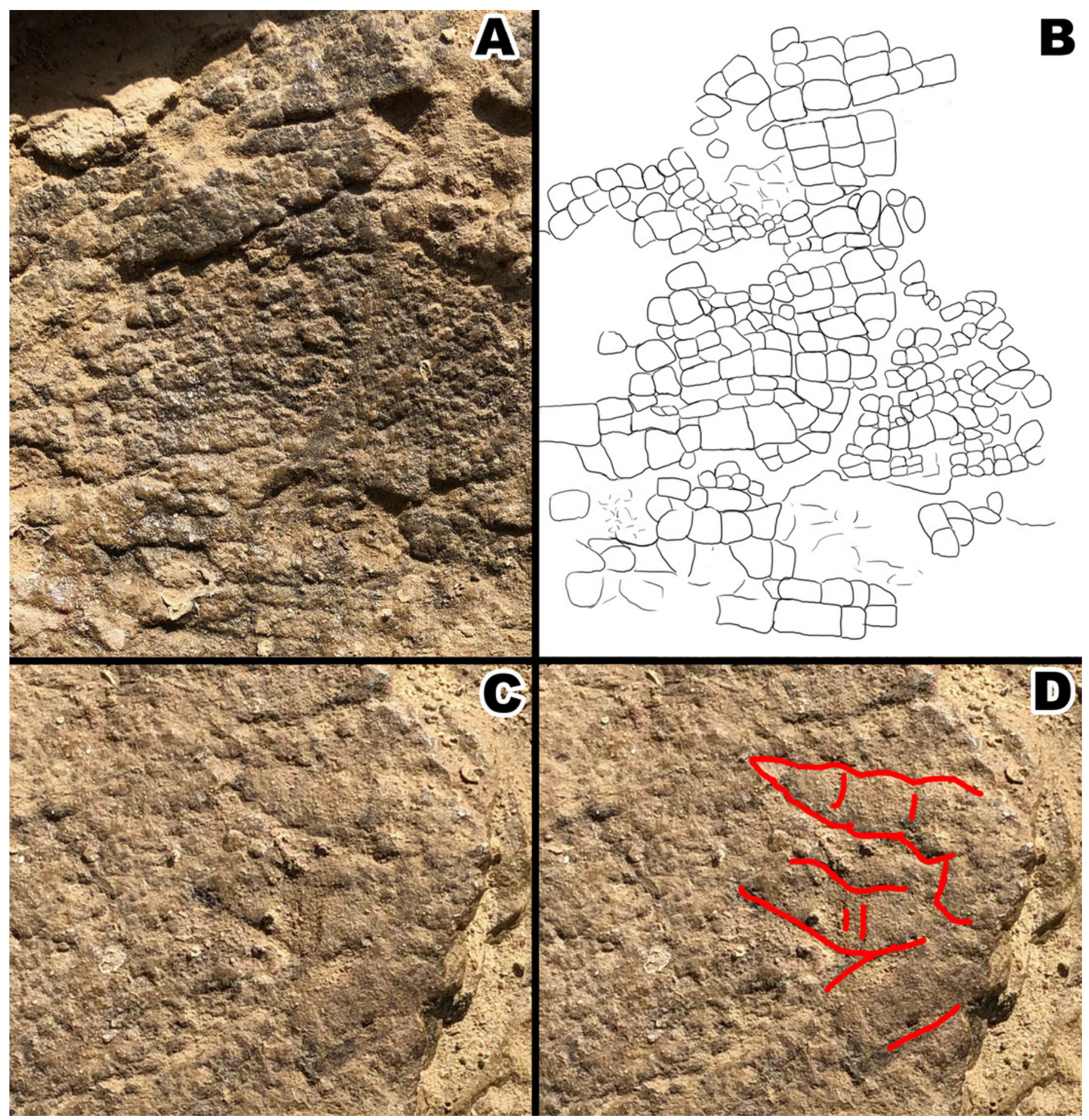


Figure 5

Close up picture of skin section branching off from section Ac containing ovoid and dome scales.

(Ac) Polygonal tubercles. (Ad) Polygonal scales of similar size to scales from Ac, these then transition into the dome $(<5 \mathrm{~mm})$ and ovoid scales $(\sim 10 \mathrm{~mm})$. (C) Pieces from fragment $C$. 


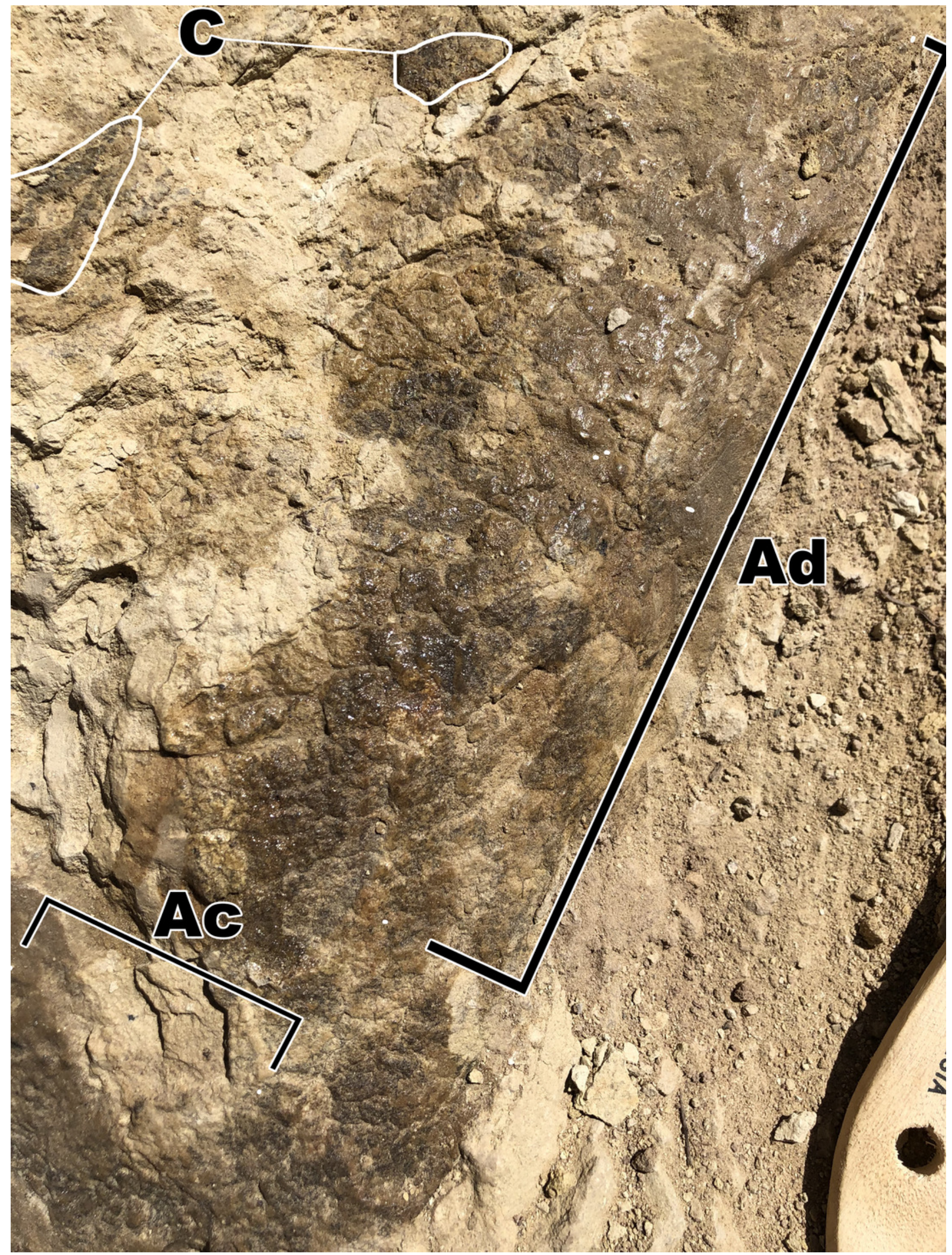


Figure 6

Close up of section Ad with a better view of unique scale shapes.

(A) Dome scales and ovoid scales oriented in a cluster orientation. (B) Interpretive drawing to help highlight oval and dome scales from section Ad. Abbreviations: d; dome scales, o; ovoid scales. Drawing by TG.

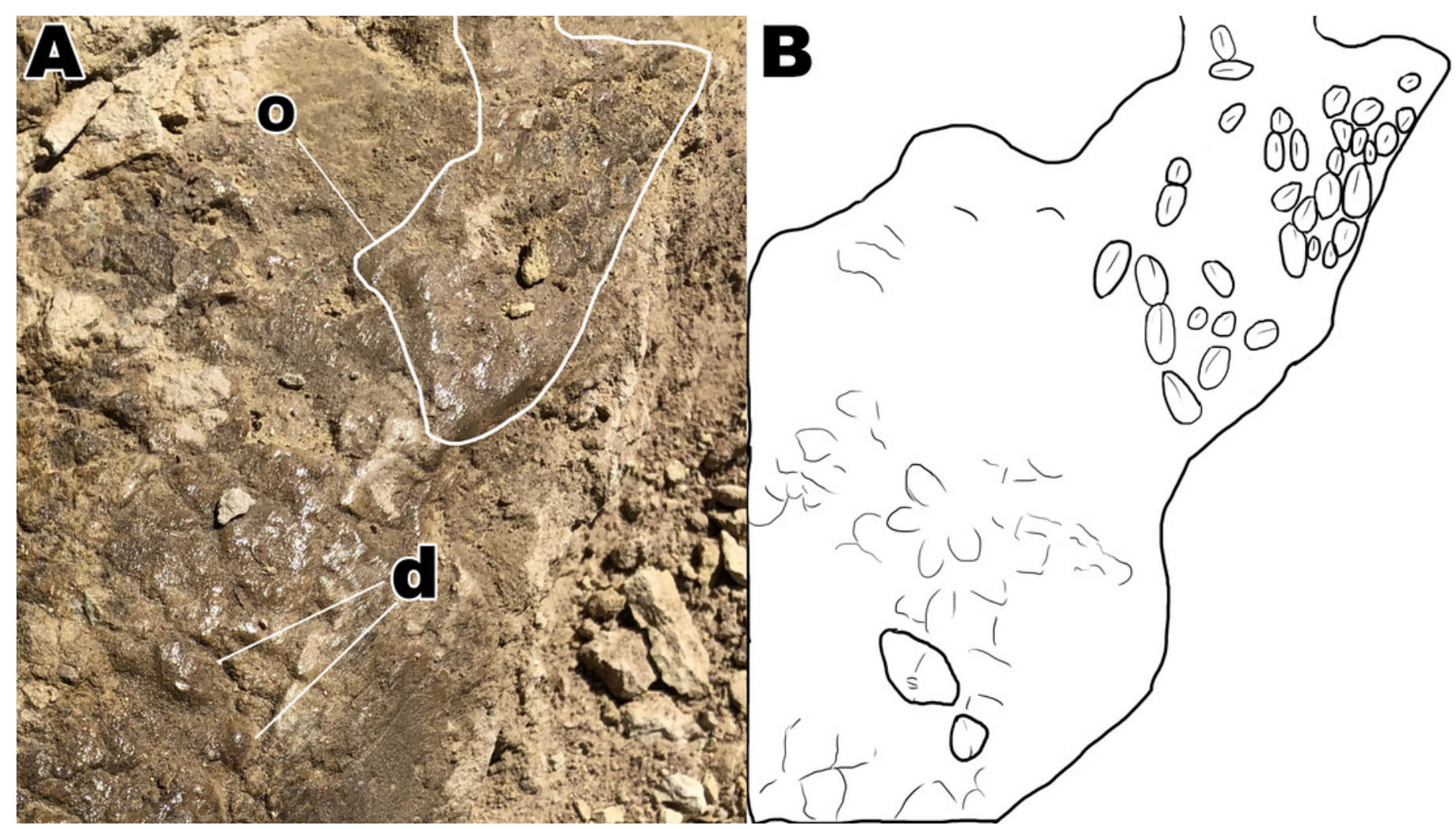


Figure 7

Skin fragment B, located on the opposite side of the rib as to fragment A.

(Ba) Smooth globular tubercles that measure $\sim 10 \mathrm{~mm}$. (Bb) Polygonal and square shaped tubercles that measure $<5 \mathrm{~mm}$. (Bc) Pebble shaped tubercles that measure $\sim 2 \mathrm{~mm}$. 


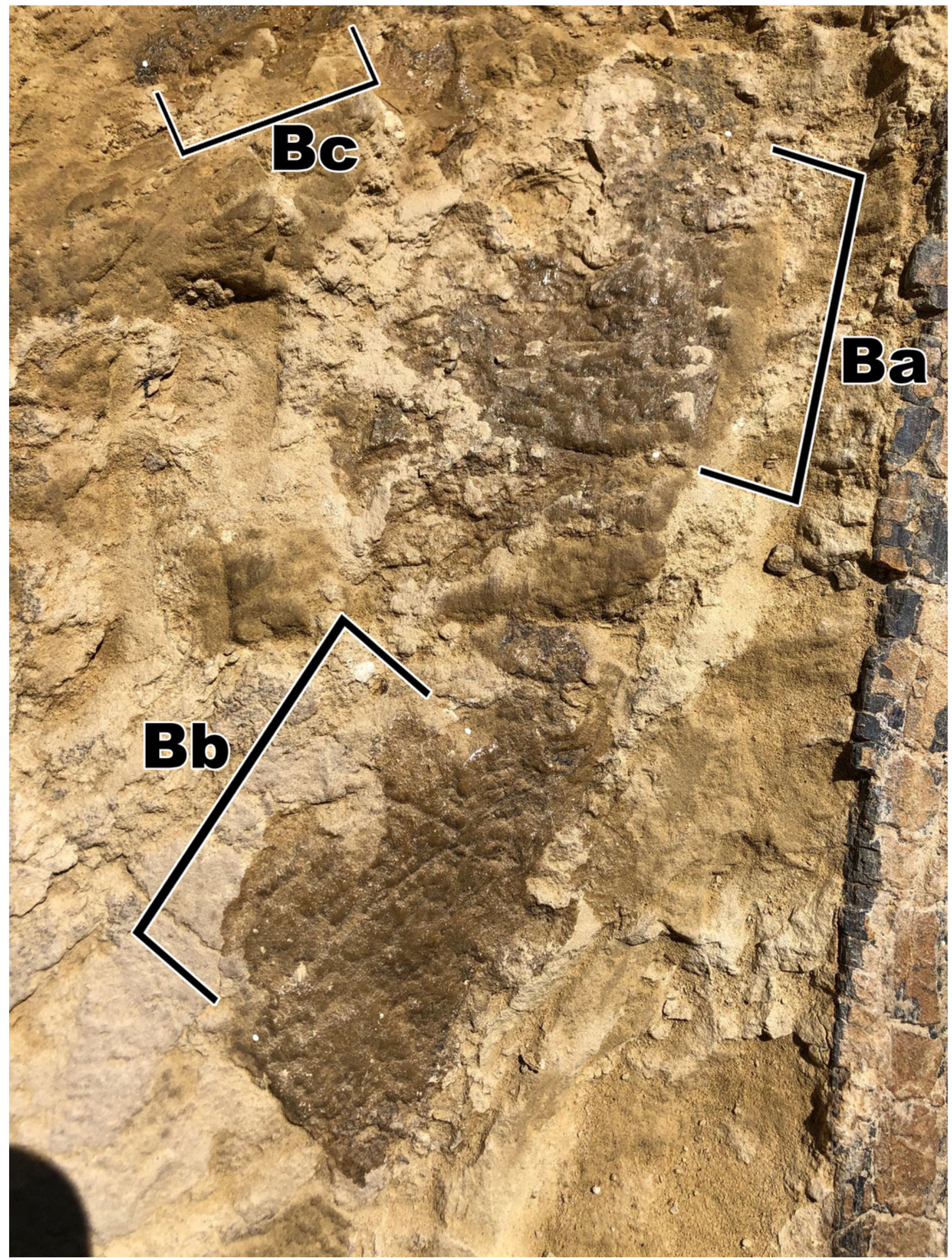


Figure 8

Close up pictures of section $\mathrm{Ba}$ and $\mathrm{Bb}$ for better view of the globular scales and arching orientation with interpretive drawings.

(A) Close up of section Bb. (B) Drawing of arching scale alignment from section Bb. (C) Close up picture of section Ba. (D) Drawing of globular scales from section Ba. Drawings by TG. 


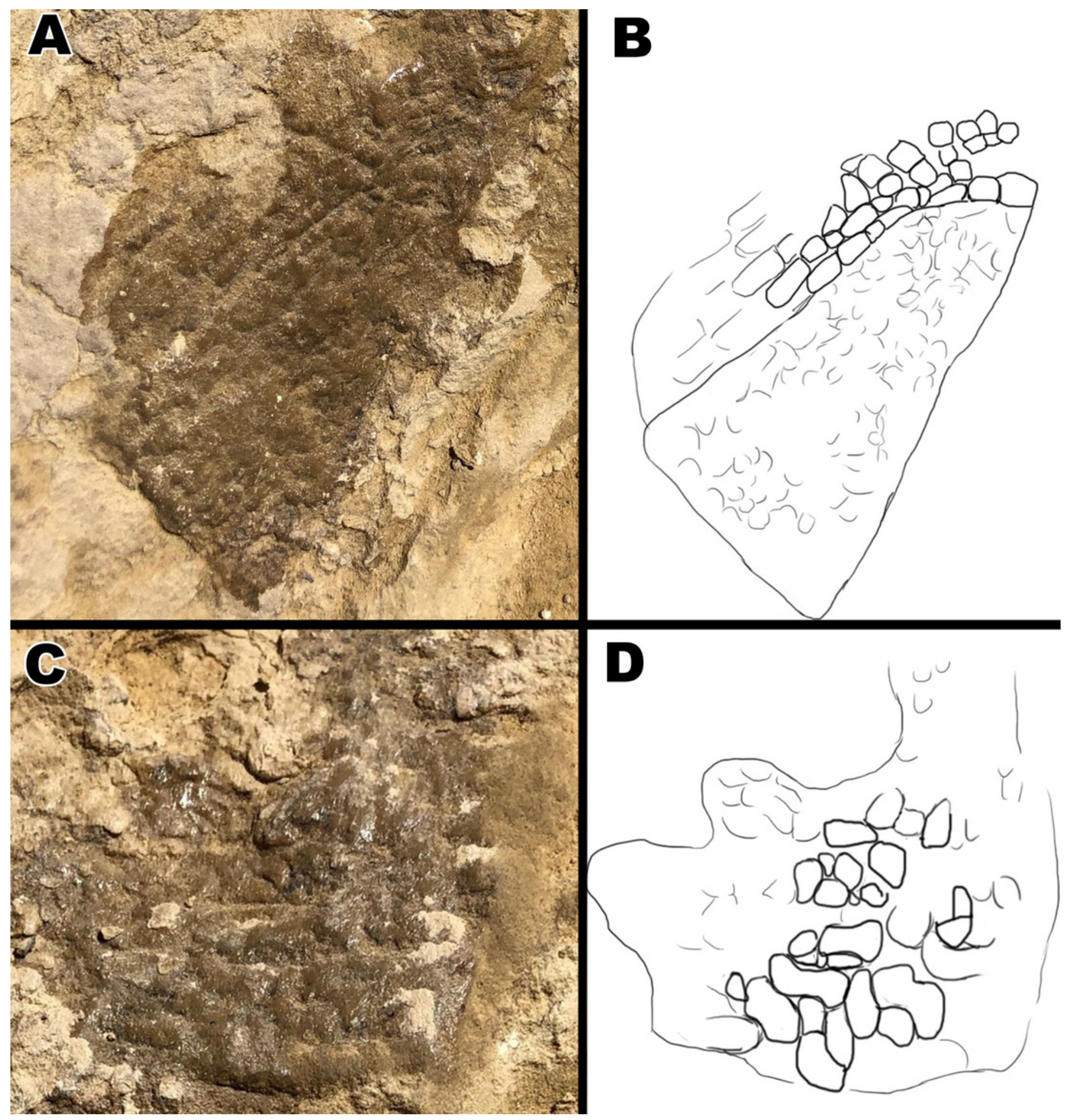


Figure 9

Comparison between scales around an Alligator mississippiensis hindlimb to downward aligned Diplodocus scales.

(A) Close up picture of section Bb. (B) Hindlimb of a juvenile Alligator with scales arching around where the back leg connects to the body. (C ) Arching scale rows of $\mathrm{Bb}$ outlined by red lines. (D) Arching scale rows of juvenile Alligator outlined with red lines. 

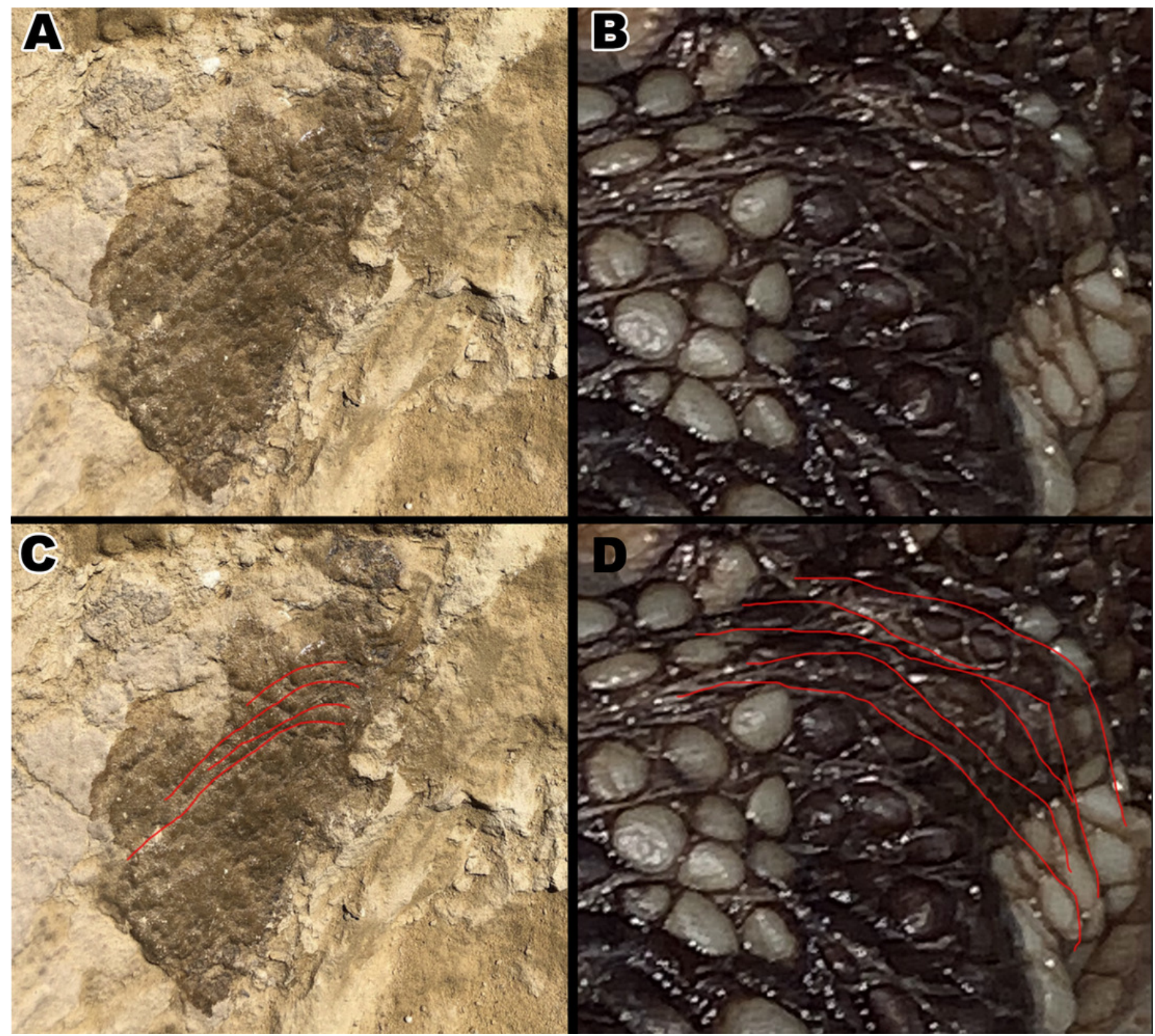
Figure 10

Skin fragment $\mathrm{C}$ with brush for size reference.

These tubercles are within close proximity to section Ad, and show similar polygonal patterning. 


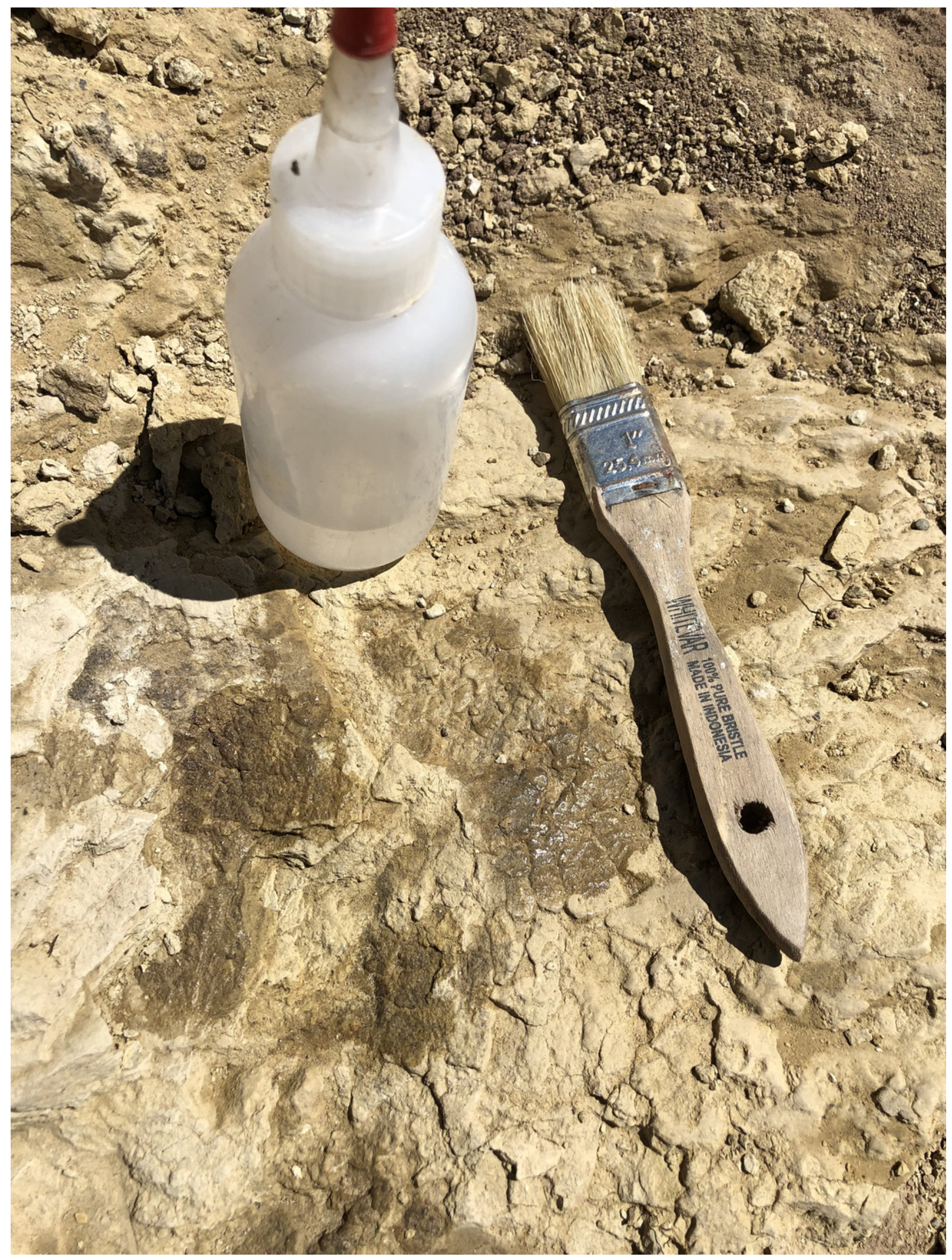


Figure 11

Distribution of scale shapes and orientations on MDS-028-2019 compared to scale shape distribution in Juravenator.

(A) Simplified drawing of distribution of scale shapes in the tail of Juravenator. Different scale shapes are indicated by color and simplified drawings of the scales. Colored squares indicate what color is associated with each scale shape. Drawing based off descriptions from Bell et al., (2020). (B) Drawing of MDS-028-2019 showing distribution of scale shape and orientation. Change in scale shape or orientation is indicated with color, as indicated by colored squares on the bottom. Drawings by TG.

A

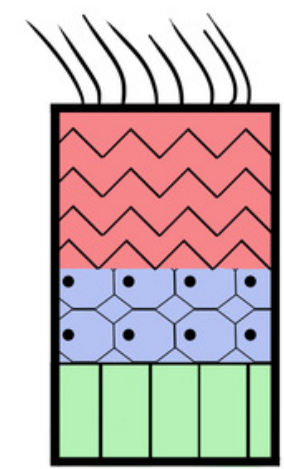

Tuberculated scales Ornamental scales Scutate ventral scales

$<5 \mathrm{~mm}$ Polygonal scales

Pebble scales

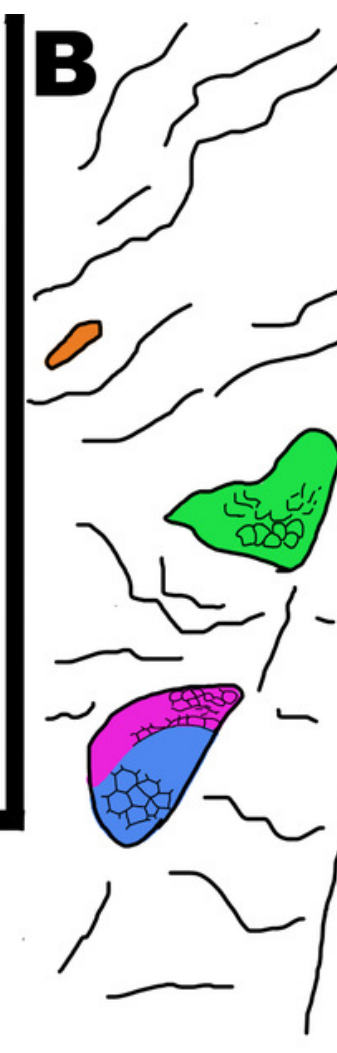

Rectangular scales

Ovoid scales

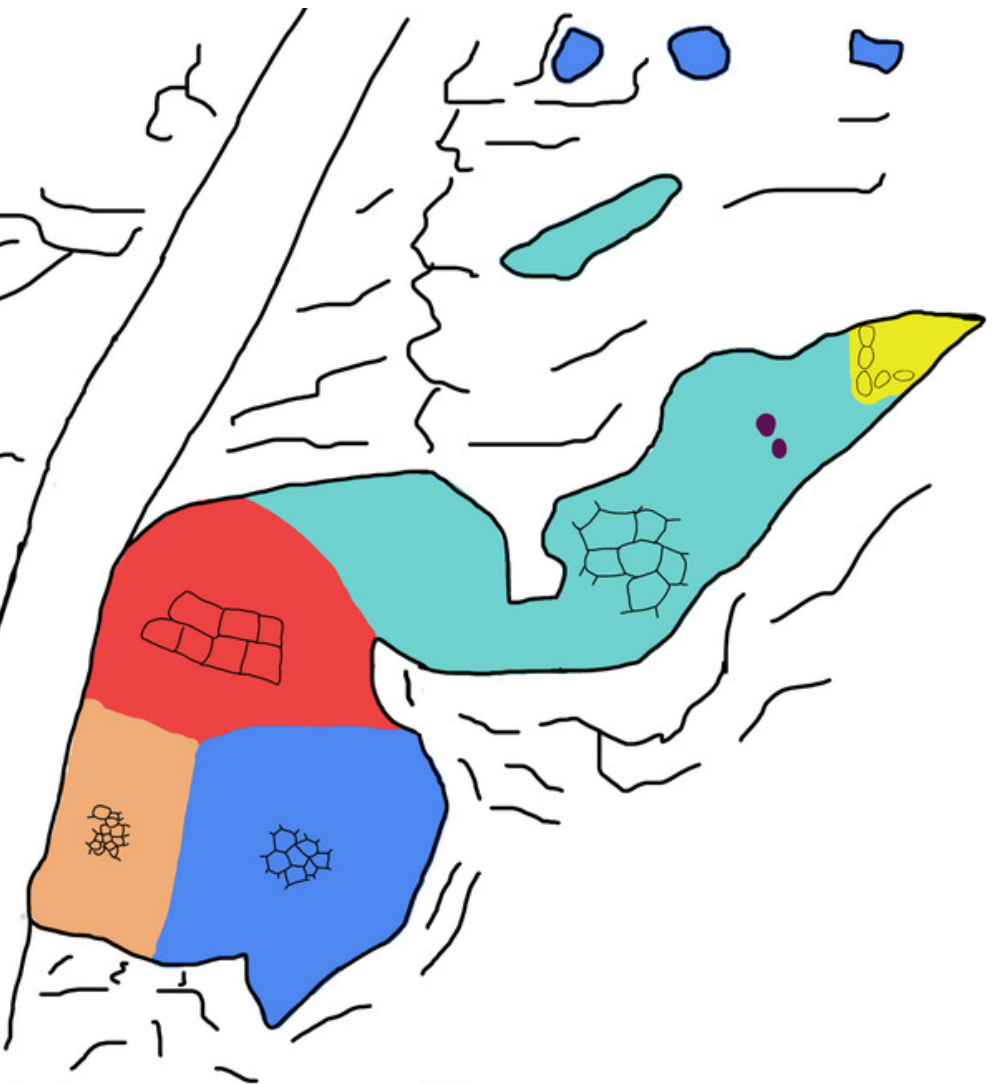

Polygonal scales

Domed scales

Arching rectangular scale rows 


\section{Figure 12}

Distribution of scale size indicated by color in MDS-028-2019 and Tehuelchesaurus.

(A) Interpretive drawing of distribution of scale size in MDS-028-2019 indicated by color. Color grading represents gradual transition in scale size, while abrupt color change indicates abrupt change in scale size. Squares indicate what color represents each scale size in $\mathrm{mm}$. (B) Interpretive drawing of distribution of scale sizes in Tehuelchesaurus ventrally and dorsally. (D) Location of scales on the body and colored squares representing scale sizes in $\mathrm{mm}$. It should be noted that it is unknown if Tehuelchesaurus had more diversity in scale size then what is known, and that the drawings are based off the idea that big scales were located dorsally and small scales located ventrally. Drawing of Tehuelchesaurus scale placement based off description from Gimenez (2007). Drawings by TG. 


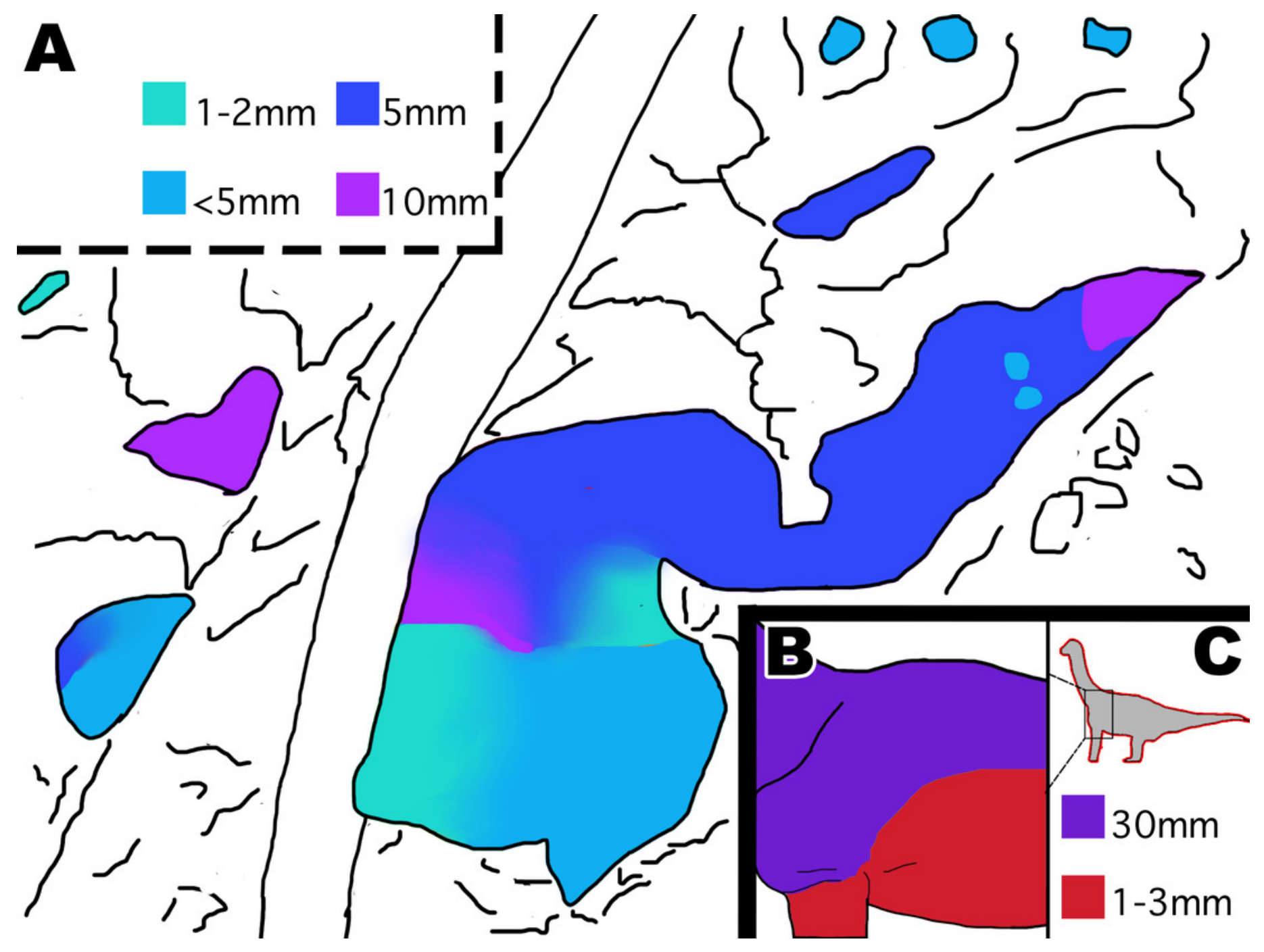

